\title{
Identification of the polymorphisms in IFITM3 gene and their association in a Korean population with ulcerative colitis
}

\author{
Geom Seog Seo ${ }^{1,3 *}$, Jeong Kun Lee ${ }^{1,3 *}$, \\ $\mathrm{Ji}$ In $\mathrm{Yu}^{2,3}$, Ki Jung Yun ${ }^{2,3}$, Soo Cheon Chae ${ }^{2,3}$ \\ and Suck Chei Choi ${ }^{1,3,4}$ \\ ${ }^{1}$ Department of Gastroenterology \\ ${ }^{2}$ Department of Pathology \\ School of Medicine, Wonkwang University \\ ${ }^{3}$ Digestive Disease Research Institute \\ Wonkwang University \\ Iksan 570-711, Korea \\ ${ }^{4}$ Corresponding author: Tel, 82-63-8592563; \\ Fax, 82-63-8552025; E-mail, medcsc@wmc.wonkwang.ac.kr \\ *These authors contributed equally to this work. \\ DOI 10.3858/emm.2010.42.2.011
}

Accepted 20 November 2009

Available Online 30 November 2009

Abbreviations: $C D$, crohn's disease; IBD, inflammatory bowel disease; IFITM3, interferon inducible transmembrane protein 3; SNP, single nucleotide polymorphism; UC, ulcerative colitis

\begin{abstract}
Interferons play critical roles in tumor pathogenesis by controlling apoptosis and through cellular anti-proliferative and differentiation activities. Interferon inducible transmembrane protein (IFITM) family genes have been implicated in several cellular processes such as the homotypic cell adhesion functions of IFN and cellular anti-proliferative activities. Expression levels of IFITM genes have been found to be up-regulated in gastric cancer cells and colorectal tumors. IFITM3 (also known as 1-8U) is a member of the IFITM family, and has been described as a key player in specification of germ cell fate. IFITM3 was first isolated from a genetic screen aimed at identifying genes involved in acquisition of germ cell competence. It has been proposed that epiblast cells have the highest expression of IFITM3 initiated germ cell specification and that homotypic association can discriminate germ cells from their somatic neighbors. In an attempt to better understand the genetic influences of IFITM3 on ulcerative colitis, we have identified possible variation sites and single nucleotide polymorphisms (SNPs) through two exons and their boundary IFITM3 intron sequences in-
\end{abstract}

cluding the $\sim 2.1 \mathrm{~kb}$ promoter regions. To determine whether or not these IFITM3SNPs are associated with susceptibility to ulcerative colitis, frequencies of the genotype and allele of IFITM3 polymorphisms were analyzed on genomic DNAs isolated from patients with ulcerative colitis and from healthy controls. We also investigated the haplotype frequencies constructed by these SNPs in both groups. In this study, we also showed that expression level of IFITM3 mRNA was significantly higher in tissues of the ileum and cecum of the digestive system. We identified a total of seven SNPs and multiple variation regions in the IFITM3 gene. The genotype frequency of the g.-204T $>G$ polymorphism in patients with ulcerative colitis was significantly different from that of the control group. Our results strongly suggest that polymorphisms of the IFITM3 gene may be associated with susceptibility to ulcerative colitis.

Keywords: colitis, ulcerative; fragilis protein, mouse; haplotypes; inflammatory bowel diseases; polymorphism, single nucleotide

\section{Introduction}

Inflammatory bowel disease (IBD) commonly refers to ulcerative colitis (UC) and Crohn's disease (CD), which is a chronic inflammatory disease of the gastrointestinal tract of unknown etiology (Blumberg et al., 1999). IBDs are complex and multifactorial involving genetic, environmental and microbial factors (Fiocchi, 1998; Podolsky, 2002). The balance between pro- and anti-inflammatory cytokines secreted by $T$ cells is responsible for both initiation and perpetuation of IBD. Cytokine production in lamina propria $\mathrm{CD}^{+} \mathrm{T}$ lymphocytes differs between $C D$ and UC. Whereas $C D$ is associated with increased production of T helper 1 cell (Th1) type cytokines, such as IFN- $\gamma$ and TNF- $\alpha$, UC is associated with T cells that produce large amounts of the Th2 type cytokine IL-5, however, IFN- $\gamma$ production is not affected (Targan et al., 1995; Fuss et al., 1996; Plevy et al., 1997).

Data from genome-wide linkage analysis has implicated multiple IBD susceptibility loci in IBD affected sibling or relative-pair families (Ahmad et al., 2004). Results from a number of studies have suggested the existence of at least nine IBD loci 
(referred to as IBD 1-9) in the human genome. Whereas some loci appear to be specific to UC (IBD2) (Parkes et al., 2000), others seem to confer susceptibility to both CD and UC (IBD3) (Satsangi et al., 1996; Hampe et al., 1999; Van Heel et al., 2004).

Interferon induced transmembrane protein 3 (IFITM3, also known as 1-8U) is a member of the IFITM family, which mediates cellular processes, including the homotypic cell adhesion functions of interferons (IFNs). Expression levels of IFITM genes have been found to be up-regulated in gastric cancer cell and colorectal tumors (Yang et al., 2005; Andreu, 2006). IFITM3 was initially cloned from a human lymphoid cell cDNA library (Lewin et al., 1991), and is located on chromosome 11 15.5 (Lange et al., 2003). Hisamatsu and colleagues reported that the IFITM3 gene demonstrated strong expression in UC-associated cancers, describing it as a preferential marker of colitis-associated colon cancer in UC (Hisamatsu et al., 1999). Although IFITM3 is one of the crucial candidate genes for IBD pathogenesis, a correlation between single nucleotide polymorphisms (SNPS) of IFITM3 and individual susceptibility to various diseases, including UC, has not been reported. In an attempt to better understand the genetic influences of IFITM3 on UC, we have identified possible variation sites and SNPs through the two exons of IFITM3 and their boundary intron sequences, including the $\sim 2.1 \mathrm{~kb}$ promoter regions. To determine whether or not these IFITM3 SNPs are associated with susceptibility to UC, genotype and allele frequencies of IFITM3 polymorphisms were analyzed on genomic DNAs isolated from patients with UC and healthy controls. We also investigated haplotype frequencies constructed by these SNPs in both groups.

\section{Results}

We examined expression patterns of IFITM3 mRNA in 15 normal human tissues and peripheral leukocytes (Figure 1). Our results showed that the expression level of IFITM3 mRNA was highest in peripheral leukocytes, while the expression level of IFITM3 mRNA in brain and thymus was barely detected (Figure 1A). We also examined expression patterns of IFITM3 mRNA in the various tissues of the human digestive system (Figure 1). The expression level of IFITM3 mRNA was significantly higher in tissues of the ileum and cecum than those in other tissues of the digestive system (Figure 1B). These results suggest that IFITM3 might modulate immune cell function and the
A

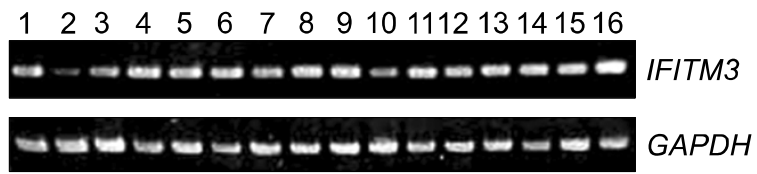

B

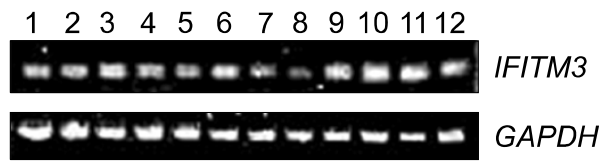

Figure 1. Expression patterns of the IFITM3 mRNA. The expression levels of IFITM3 mRNA in various human tissues: 1, lung; 2, brain; 3 , muscle; 4 pancreas; 5 , kindey; 6 , placenta; 7 , heart; 8 , liver; 9 , spleen; 10 , thymus; 11 , prostate; 12 , testis; 13 , ovary; 14 , intestine; 15, colon; 16 , leukocyte (A), and the tissues of human digestive system: 1 , liver; 2 , stomach; 3 , colon (desending); 4, colon (transverse); 5, colon (ascending); 6, ileocecum; 7, duodenum; 8 , rectum; 9 , jejunum; 10, ileum; 11, cecum; 12, esophagus (B).

intestinal immune system.

To determine variation sites in the IFITM3 gene, including the promoter region ( 2.0 kb), we scanned genomic DNAs isolated from 48 unrelated controls using direct sequence analysis. We identified a total of seven SNPs, g.-1129G $>A$ (novel SNP) in the promoter region, g. $-204 T>G$ (rs3888188), g. $-188 T>C$ (rs6598045), g.-181T>C (rs7478728 ), g.-178A $>C$ (novel SNP), g.-175T $>C$ (rs7479267) in the 5 '-UTR region, and $g .42 C>T$ (rs12252) in the exon 1 (Figure 2). The g.42C $>T$ polymorphism located in the coding region was synonymous SNP (Ser14Ser). To identify multiple variation sites in the promoter region, PCR and sequencing analysis were performed using IFITM3-SF2 and IFITM3-SR2 primers (Figure 2). There exist at least five types with the difference length by repeated sequence (data not shown). Linkage disequilibrium coefficients (|D'|) between all SNP pairs were calculated, and found the absolute LD $\left(\left|D^{\prime}\right|=1\right.$ and $\left.r^{2}=1\right)$ between g. $-204 T>G$ and $g .-178 A>C$ (data not shown). Among the polymorphisms identified in this study, three SNPS (g.-204T>G, g.-175T>C and $g$. $42 C>T$ ) were selected for large samples genotype analysis. The D' values between g.-204T $>G$ and g. $-175 T>C$ (or g. $42 C>T$ ) were 0.617 and 0.943 , respectively, and between $g .-175 T>C$ and $g$. $42 C>T$ was -0.873 (data not shown). We analyzed genotype and allele frequencies of patients with UC and healthy controls (Table 1, co-dominant analysis). In patients with UC, genotype frequency of the g.-204T $>G$ polymorphism was significantly different from the frequency of the healthy control group $(P=0.0146)$. 


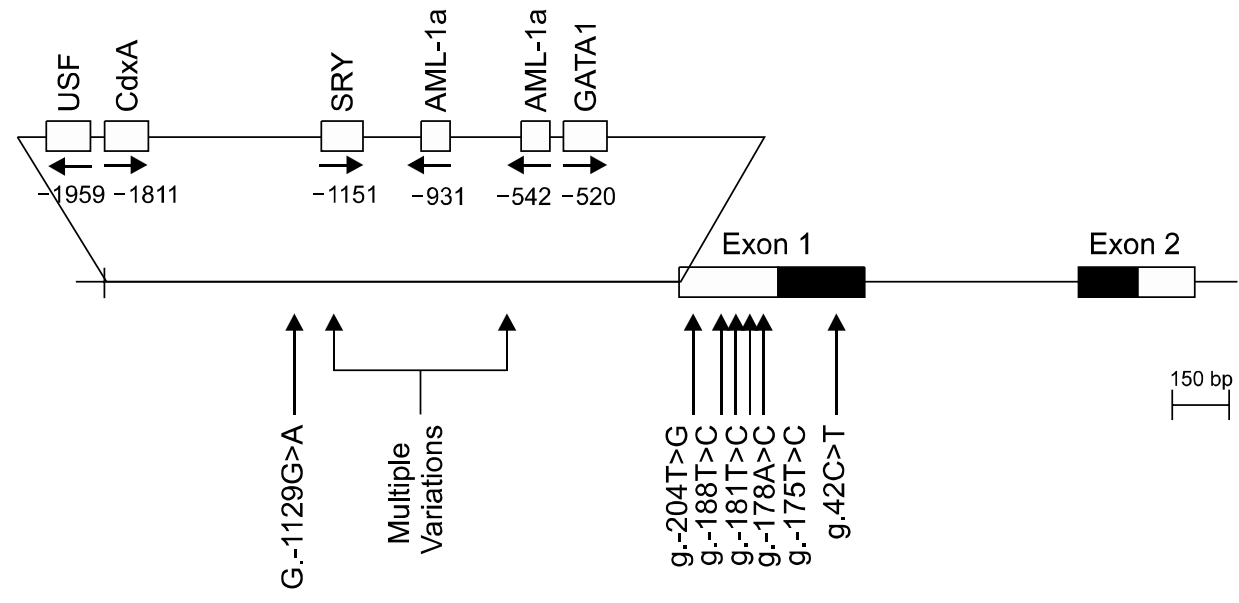

Figure 2. Locations of each single nucleotide polymorphisms (SNPs) and variation sites in IFITM3. Coding exons are marked by black blocks and 5'- and 3'-UTR by white blocks. The positions of SNPs were calculated from the translation start site. Putative transcription factor sites were searched at www.cbrc. jp/research/db/TFSEARCH.html. The reference sequence for IFITM3 was based on the sequence of human chromosome 11, clone RP13$317 \mathrm{D} 12$.
We also evaluated haplotype frequencies among g. $-204 T>G$, g. $-175 T>C$ and $g .42 C>T$ polymorphisms in both healthy controls and patients with UC (Table 2). While four major (more than $5 \%$ ) haplotypes explaining more than $95.1 \%$ of distributions were identified in patients with UC, three major haplotypes $(95.3 \%)$ out of eight possible haplotypes were identified in the healthy control group. The distribution of haplotype TCT and GTT were significantly different between healthy controls and patients with UC $(P=0.001$ and $P=$ 0.015 , respectively). These results suggested that IFITM3 polymorphisms might be one of the most important genetic factors in IBD susceptibility.

\section{Discussion}

During the developmental stage, the activated Th cells differentiate into two phenotypically and functionally distinct cell types, Th1 and Th2 (Mosmann and Coffman, 1989; Abbas et al., 1996). Th1 cells produce the cytokines IFN- $\gamma$, IL-2 and lymphotoxin, which are commonly associated with cell-mediated immune response to intracellular pathogens and induction of organ-specific autoimmune disease (Kuchroo et al., 1995; Abbas et al., 1996). On the other hand, the Th2 cell related cytokines IL-4, IL-5, and IL-10, have a known association with atopic and allergic diseases. Th1 and Th2 cells cross-regulate one another in their differentiation. In IBD, UC is associated with T cells

Table 1. Genotype and allele analyses of the polymorphisms of IFITM3 gene in UC patients and healthy controls.

\begin{tabular}{|c|c|c|c|c|c|}
\hline Position* & Genotype/Allele & Control n (\%) & UC n (\%) & Odds ratio $^{\dagger}(95 \% \mathrm{Cl})$ & $P^{\ddagger}$ \\
\hline \multirow[t]{5}{*}{ g.-204T > G (rs3888188) } & GG & $238(42.1)$ & $71(39.0)$ & 1.00 & 0.0146 \\
\hline & GT & $278(49.1)$ & 81 (44.5) & $0.98(0.68-1.40)$ & \\
\hline & TT & $50(8.8)$ & $30(16.5)$ & $2.01(1.19-3.40)$ & \\
\hline & $G$ & $754(66.6)$ & $223(61.3)$ & 1.00 & 0.0665 \\
\hline & $\mathrm{T}$ & $378(33.4)$ & $141(38.7)$ & $1.261(0.99-1.61)$ & \\
\hline \multirow{5}{*}{ g. $-175 \mathrm{~T}>\mathrm{C}(\mathrm{rs} 7479267)$} & $\mathrm{TT}$ & $336(60.3)$ & $100(54.9)$ & 1.00 & 0.0726 \\
\hline & $\mathrm{TC}$ & $198(35.6)$ & $67(36.8)$ & $1.14(0.80-1.62)$ & \\
\hline & $\mathrm{CC}$ & $23(4.1)$ & $15(8.2)$ & $2.19(1.10-4.36)$ & \\
\hline & $\mathrm{T}$ & $870(78.1)$ & $267(73.4)$ & 1.00 & 0.0730 \\
\hline & C & $244(21.9)$ & $97(26.6)$ & $1.30(0.99-1.70)$ & \\
\hline \multirow[t]{5}{*}{ g.42C > T (rs12252) } & $\mathrm{CC}$ & $202(36.2)$ & $60(33.0)$ & 1.00 & 0.2818 \\
\hline & $\mathrm{CT}$ & $281(50.4)$ & $89(48.9)$ & $1.07(0.73-1.55)$ & \\
\hline & TT & $75(13.4)$ & $33(18.1)$ & $1.48(0.90-2.44)$ & \\
\hline & C & $685(61.4)$ & $209(57.4)$ & 1.00 & 0.1950 \\
\hline & $\mathrm{T}$ & $431(38.6)$ & $155(42.6)$ & $1.18(0.93-1.50)$ & \\
\hline
\end{tabular}

${ }^{*}$ Calculated from the translation start site. ${ }^{\dagger}$ Logistic regression analyses were used for calculating OR $\left(95 \% \mathrm{Cl}\right.$; confidence interval). ${ }^{\ddagger}$ Value was determined by Fisher's exact test or $\chi^{2}$ test from $2 \times 2$ contingency table. 
Table 2. The haplotype frequencies in both IBD patients and controls in IFITM3 polymorphisms.

\begin{tabular}{|c|c|c|c|c|c|c|}
\hline \multicolumn{3}{|c|}{ Haplotype } & \multicolumn{2}{|c|}{ Frequency* } & \multirow{2}{*}{ Chi-square } & \multirow{2}{*}{$P^{\dagger}$} \\
\hline g. $-204 T>$ G & g. $-175 \mathrm{~T}>\mathrm{C}$ & $\mathrm{g} .42 \mathrm{C}>\mathrm{T}$ & UC & Control & & \\
\hline$G$ & $T$ & C & 0.566 & 0.575 & 0.094 & 0.759 \\
\hline $\mathrm{T}$ & $\mathrm{C}$ & $\mathrm{T}$ & 0.265 & 0.185 & 10.88 & 0.001 \\
\hline $\mathrm{T}$ & $\mathrm{T}$ & $\mathrm{T}$ & 0.116 & 0.108 & 0.156 & 0.692 \\
\hline G & $\mathrm{T}$ & $\mathrm{T}$ & 0.045 & 0.083 & 5.900 & 0.015 \\
\hline $\mathrm{T}$ & $\mathrm{C}$ & C & 0.003 & 0.024 & 6.671 & 0.009 \\
\hline $\mathrm{T}$ & $\mathrm{T}$ & C & 0.006 & 0.014 & 1.603 & 0.206 \\
\hline $\mathrm{G}$ & $\mathrm{C}$ & $\mathrm{T}$ & $1.2 \mathrm{E}-9$ & 0.011 & 3.942 & 0.047 \\
\hline
\end{tabular}

*Values were constructed by EM algorithm with genotyped SNPs. ${ }^{\dagger}$ Values were analyzed by Chi-square.

production of large amounts of Th2-type cytokines and eosinophils (Plevy et al., 1997; Farrell, 2002). There are many differences regarding disease extension, localization, behavior, and occurrence of extra- intestinal manifestations within UC (Forbes, 2003; Travis and Jewell, 2003).

Multiple IBD susceptibility loci (IBD 1-9) have been implicated. Among these loci, IBD1 and IBD3 are the most extensively studied genetic regions in IBD. The human leucocyte antigen (HLA) complex is located on the IBD3 locus (Williams et al., 2002; van Heel et al., 2004). HLA class II variants are associated with the susceptibility and phenotype in both CD and UC (Satsangi et al., 1996; Hampe et al., 1999; Stokkers et al., 1999; Yang et al., 1999; Dechairo et al., 2001). We previously reported on the exon 4 variation of the Tim-1 gene, and the polymorphisms of eotaxin-2 and eotaxin-3 are associated with UC in the Korean population (Song et al., 2004; Park et al., 2005).

The human IFITM3 gene, a member of the IFITM family, consists of two exons and one intron. IFITM proteins were first discovered in T98G neuroblastoma cells that express the proteins in response to interferon stimulation (Friedman et al. 1984). These proteins play distinct roles in mouse primordial germ cell homing and repulsion (Tanaka et al. 2005). In the aspect of gastrointestinal tract, IFITM3 gene was first isolated from colitis-associated cancer tissues and severely inflamed mucosa in the colon of UC patients using differential display PCR (Hisamatsu et al. 1999). Although the IFITM3 gene may be an important candidate gene for UC, few results for this gene have been published; therefore, the precise function of the IFITM3 gene is unknown, there has been no research on genetic variation. The IFITM3 gene was recently identified, and several reports have suggested that IFITM3 is one of the crucial candidate genes for IBD (Wu et al. 2007). In this study, we showed that expression level of IFITM3 mRNA was significantly higher in the ileum and cecum tissues of the human digestive system. We identified a total of seven SNPs and multiple variation regions in the IFITM3 gene. The genotype frequency of g.-204T>G polymorphisms in patients with UC was significantly different from that of the healthy control group (Table 2). This result strongly suggests that SNPs of IFITM3 may be associated with susceptibility to UC. Polymorphisms within the binding site of the promoter region may influence expression level, by suppression of binding between the specific transcriptional binding site, and the transcription factor. Accordingly, it is interesting to know that the IFITM3 polymorphism (g.-204T>G) may have some influence on susceptibility to UC. Thus, our results will be important in future studies, to determine whether or not this polymorphism affects the levels of IFITM3 gene expression and function. In summary, our results strongly suggest that polymorphisms of the IFITM3 gene may be associated with susceptibility to UC, as well as the TCT haplotype, by g.-204T>G, g. $-175 T>C$, and g. $42 C>T$ polymorphisms in the IFITM3 gene, and may be an important genetic marker for IBD.

\section{Methods}

\section{Patients and DNA samples}

Blood samples were obtained from 183 UC patients (100 males and 83 females) and 566 healthy controls (351 males and 215 females). Mean ages of IBD patients and controls were $41.1 \mathrm{yr}$ and $40.5 \mathrm{yr}$, respectively. Genomic DNA was extracted from leukocyte in peripheral blood by use of a standard phenol-chloroform method or by use of a Genomic DNA Extraction kit (iNtRON Biotechnology, Korea) according to the manufacturer's directions. IBD patients were recruited from the outpatient clinic at Wonkwang University Hospital. Patients were classified into the IBD group according to clinical features, endoscopic findings, and histopathologic examinations. Healthy controls were recruited from the general population, and had received comprehensive medical testing at the 
Wonkwang University Hospital. All subjects in this study were Korean.

\section{PCR and sequence analysis}

The entire coding regions of the IFITM3 gene, including the $\sim 2.0 \mathrm{~kb}$ promoter regions, were partially amplified by PCR using the two primer pairs (Supplemental Data Table S1). PCR reactions were prepared by previously described procedures (Chae et al., 2004). Amplification was carried out in a GeneAmp PCR system 9700 thermocycler (PE Applied Biosystem) at $95^{\circ} \mathrm{C}$ for $5 \mathrm{~min}$ in order to pre-denature the template DNA, followed by 30 cycles of denaturation at $98^{\circ} \mathrm{C}$ for $10 \mathrm{~s}$, annealing at $68^{\circ} \mathrm{C}$ for $30 \mathrm{~s}$ and extension at $72^{\circ} \mathrm{C}$ for 2.0 or $2.5 \mathrm{~min}$. The final extension was completed at $72^{\circ} \mathrm{C}$ for $7 \mathrm{~min}$. PCR products purified by use of a PCR purification kit (Millipore) were used template DNA for sequencing analysis. Purified PCR products were sequenced using the $\mathrm{ABI}$ Prism BigDye Terminator cycle sequencing system (PE Applied Biosystems) on the ABI 3100 automatic sequencer (PE Applied Biosystem). Both sense and antisense strands of PCR products were directly sequenced using the same primers used for the PCR amplification, and five primers were additionally used to sequence the promoter and intron 1 region (Supplemental Data Table S1). SNPs and variation sites of the IFITM3 gene were detected by direct sequence analysis. The reference sequence for the IFITM3 gene was based on the sequence of human chromosome 11, clone RP13- 317D12.

\section{IFITM3 mRNA expression level}

The expression level of IFITM3 mRNA in various tissues was determined using MTC multiple tissue cDNA panels (Clontech, CA), and IFITM3-MF1 and IFITM3-MR1 primers (Supplemental Data Table S1).

\section{PCR-RFLP}

Genotyping for $g .42 T>C$ in the IFITM3 gene was performed by PCR-RFLP. A region of the IFITM3 gene containing the $g .42 T>C$ polymorphism was partially amplified by PCR using the IFITM3-PF2 and IFITM3-SR1 primer pairs (Supplemental Data Table S1). PCR products were digested with 1 units of Bal I (Takara Co., Ltd., Japan) for $3 \mathrm{~h}$ at $37^{\circ} \mathrm{C}$, and then separated on $1.5 \%$ agarose gel and visualized under UV with ethidium bromide. Following restriction enzyme digestion, the PCR products for g. $42 T>C(1,357 \mathrm{bp})$ took the form of two fragments, of $776 \mathrm{bp}$ and $581 \mathrm{bp}$ (Supplemental Data Figure S1).

\section{Single-base extension (SBE)}

Genotype analysis for g.-175T $>G$ and g.-204T>G in the IFITM3 gene was performed by way of single-base extension (SBE), using the $A B I$ Prism ${ }^{\circledR}$ SNaPshot $^{T M}$ Multiplex kit (Applied Biosystems). PCR products purified with a PCR purification kit (Millipore) were used as template DNA for two SBE primers (Supplemental Data Table S1). The SBE reaction mix was prepared according to the manufacturer's directions. The primer extension reaction was performed at $96^{\circ} \mathrm{C}$ for $1 \mathrm{~min}$, followed by 25 cycles at $96^{\circ} \mathrm{C}$ for $10 \mathrm{~s}, 55^{\circ} \mathrm{C}$ for $40 \mathrm{~s}$, and $60^{\circ} \mathrm{C}$ for $30 \mathrm{~s}$. To clean up the primer extension reaction, 1.5 units of CIP (Promega) was added to the reaction mixture; the mixture was incubated at $37^{\circ} \mathrm{C}$ for $90 \mathrm{~min}$, followed by $15 \mathrm{~min}$ at $72^{\circ} \mathrm{C}$, for the purposes of enzyme inactivation. Purified extension products were added to $\mathrm{Hi}-\mathrm{Di}$ formamide (Applied Biosystems) and incubated at $95^{\circ} \mathrm{C}$ for $5 \mathrm{~min}$, followed by $5 \mathrm{~min}$ on ice; electrophoresis was then performed using the $A B I$ Prism 3100 Genetic Analyzer. Results were analyzed using the ABI Prism GeneScan and Genotyper software (Applied Biosystems).

\section{Statistic analysis}

IBD patients and control groups were compared using case-control association analysis. The $\chi^{2}$ test was used to estimate Hardy-Weinberg equilibrium (HWE). Allele frequency was defined as the percentage of individuals carrying the allele among the total number of individuals. Logistic regression analyses were used to calculate odds ratios $(95 \%$ confidence interval) for SNP sites. Linkage Disequilibrium (LD) analyses by pair-wise comparison of biallelic loci and haplotype frequencies of the IFITM3 gene for multiple loci were estimated using the expectation maximization (EM) algorithm with SNPAlyze software (DYNACOM, Japan). A $P$-value of less than 0.05 was considered an indication of statistical significance.

\section{Supplemental data}

Supplemental Data include a table and a figure and can be found with this article online at http://e-emm.or.kr/article/ article_files/SP-42-2-03.pdf.

\section{Acknowledgements}

This work was supported by a grant from Wonkwang University 2009.

\section{References}

Abbas AK, Murphy KM, Sher A. Functional diversity of helper T lymphocytes. Nature 1996;383:787-93

Ahmad T, Tamboli CP, Jewell D, Colombel JF. Clinical relevance of advances in genetics and pharmacogenetics of IBD. Gastroenterology 2004;126:1533-49

Andreu P, Colnot S, Godard C, Laurent-Puig P, Lamarque D, Kahn A, Perret C, Romagnolo B. Identification of the IFITM family as a new molecular marker in human colorectal tumors. Cancer Res 2006;66:1949-55

Blumberg RS, Saubermann LJ, Strober W. Animal models of mucosal inflammation and their relation to human inflammatory bowel disease. Curr Opin Immunol 1999;11: 648-56

Chae SC, Song JH, Pounsambath P, Yuan HY, Lee JH, Kim $\mathrm{JJ}$, Lee YC, Chung HT. Molecular variations in Th1-specific cell surface gene Tim-3. Exp Mol Med 2004;36:274-8 
Dechairo B, Dimon C, van Heel D, Mackay I, Edwards M, Scambler P, Jewell D, Cardon L, Lench N, Carey A. Replication and extension studies of inflammatory bowel disease susceptibility regions confirm linkage to chromosome 6p (IBD3). Eur J Hum Genet 2001;9:627-33

Farrell RJ. Ulcerative colitis. Lancet 2002;359:331-40

Fiocchi C. Inflammatory bowel disease: etiology and pathogenesis. Gastroenterology 1998;115:182-205

Forbes A. Clinical presentation and diagnosis of Crohn's disease. In: Satsangi J and Sutherland L, eds. Inflammatory Bowel Disease. New York: Churchill Livingstone, 2003: 183-9

Friedman RL, Manly SP, McMahon M, Kerr IM, Stark GR. Transcriptional and posttranscriptional regulation of interferon-induced gene expression in human cells. Cell 1984;38:745-55

Fuss IJ, Neurath M, Boirivant M, Klein JS, de la Motte C, Strong SA, Fiocchi C, Strober W. Disparate CD4+ lamina propria (LP) lymphocyte secretion profiles in inflammatory bowel disease. Crohn's disease LP cells manifest increased secretion of IFN- $\gamma$, whereas, ulcerative colitis LP cells manifest increased secretion of IL-5. J Immunol 1996; 157:1261-70

Hampe J, Schreiber S, Shaw SH, Lau KF, Bridger S, Macpherson AJ, Cardon LR, Sakul H, Harris TJ, Buckler A, Hall J, Stokkers P, van Deventer SJ, Nürnberg P, Mirza MM, Lee JC, Lennard-Jones JE, Mathew CG, Curran ME. A genomewide analysis provides evidence for novel linkages in inflammatory bowel disease in a large European cohort. Am J Hum Genet 1999;64:808-16

Hisamatsu T, Watanabe M, Ogata H, Ezaki T, Hozawa S, Ishii $\mathrm{H}$, Kanai T, and Hibi T. Interferon-inducible Gene Family 1-8U Expression in Colitis-associated Colon Cancer and Severely Inflamed Mucosa in Ulcerative Colitis. Cancer Res 1999;59: 5927-31

Kuchroo VK, Das MP, Brown JA, Ranger AM, Zamvil SS, Sobel RA, Weiner HL, Nabavi N, Glimcher LH. B7-1 and B7-2 costimulatory molecules differentially activate the TH1/TH2 developmental pathways: application to autoimmune disease therapy. Cell 1995;80:707-16

Lange UC, Saitou M, Western PS, Barton SC, Surani MA. The fragilis interferon-inducible gene family of transmembrane proteins is associated with germ cell specification in mice. BMC Dev Biol 2003;3:1

Lewin AR, Reid LE, McMahon M, Stark GR, Kerr IM. Molecular analysis of a human interferon-inducible gene family. Eur J Biochem 1991;199:417-23

Mosmann TR, Coffman RL. TH1 and TH2 cells: different patterns of lymphokine secretion lead to different functional properties. Annu Rev Immunol 1989;7:145-73

Nayar M, Rhodes JM. Management of inflammatory bowel disease. Postgrad Med J 2004;80:206-13

Park YR, Choi SC, Lee ST, Kim KS, Chae SC, Chung HT. The association of eotaxin-2 and eotaxin-3 gene polymorphisms in a Korean population with ulcerative colitis. Exp Mol Med 2005;37:553-8
Parkes M, Barmada MM, Satsangi J, Weeks DE, Jewell DP, Duerr RH. The IBD2 locus shows linkage heterogeneity between ulcerative colitis and Crohn disease. Am J Hum Genet 2000;67:1605-10

Plevy SE, Landers CJ, Prehn J, Carramanzana NM, Deem RL, Shealy D, Targan SR. A role for TNF-alpha and mucosal Thelper-1 cytokines in the pathogenesis of Crohn's disease. J Immunol 1997;159:6276-82

Podolsky DK. Inflammatory bowel disease. N Engl J Med 2002;347:417-29

Satsangi J, Welsh KI, Bunce M, et al. Contribution of genes of the major histocompatibility complex to susceptibility and disease phenotype in inflammatory bowel disease. Lancet 1996;347:1212-7

Song JH, Choi SC, Lee ST, Lee JH, Chae SC, Chung HT. The exon 4 variations of Tim- 1 gene is not associated with allergic rhinitis and ulcerative colitis in Koreans. Korean J Genetics 2004;26:193-7

Stokkers PC, Reitsma PH, Tytgat GN, van Deventer SJ. HLA-DR and -DQ phenotypes in inflammatory bowel disease: a metaanalysis. Gut 1999;45:395-401

Tanaka SS, Yamaguchi YL, Tsoi B, Lickert H, Tam PP. IFITM/Mil/fragilis family proteins IFITM1 and IFITM3 play distinct roles in mouse primordial germ cell homing and repulsion. Dev Cell 2005;9:745-56

Targan SR, Deem RL, Liu M, Wang S, Nel A. Definition of a lamina propria $T$ cell responsive state. Enhanced cytokine responsiveness of $T$ cells stimulated through the CD2 pathway. J Immunol 1995;154:664-75

Travis S, Jewell DP. Ulcerative colitis: clinical presentation and diagnosis. In: Satsangi $\mathrm{J}$ and Sutherland LR, eds. Inflammatory Bowel Disease. New York: Churchill Livingstone, 2003:169-82

Van Heel DA, Fisher SA, Kirby A, Daly MJ, Rioux JD, Lewis CM. Inflammatory bowel disease susceptibility loci defined by genome scan meta-analysis of 1952 affected relative pairs. Hum Mol Genet 2004;13:763-70

Williams CN, Kocher K, Lander ES, Daly MJ, Rioux JD. Using a genome-wide scan and meta-analysis to identify IBD loci. Inflamm Bowel Dis 2002;8:375-81

Wu F, Dassopoulos T, Cope L, Maitra A, Brant SR, Harris ML, Bayless TM, Parmigiani G, Chakravarti S. Genome-wide Gene Expression Differences in Crohn's Disease and Ulcerative Colitis from Endoscopic Pinch Biopsies: Insights into Distinctive Pathogenesis. Inflamm Bowel Dis 2007;13: 807-21

Yang H, Plevy SE, Taylor K, Tyan D, Fischel-Ghodsian N, McElree C, Targan SR, Rotter JI. Linkage of Crohn's disease to the major histocompatibility complex region is detected by multiple non-parametric analyses. Gut 1999;44:519-26

Yang Y, Lee JH, Kim KY, Song HK, Kim JK, Yoon SR, Cho $D$, Song KS, Lee $Y H$, Choi I. The interferon-inducible 9-27 gene modulates the susceptibility to natural killer cells and the invasiveness of gastric cancer cells. Cancer Lett 2005; 221:191-200 